\title{
Identification of Active Phase for Selective Oxidation of Benzyl Alcohol with Molecular Oxygen Catalyzed by Copper-Manganese Oxide Nanoparticles
}

\author{
Roushown Ali, S. F. Adil, Abdulrahman Al-warthan, and M. Rafiq H. Siddiqui \\ Department of Chemistry, College of Science, King Saud University, P.O. Box 2455, Riyadh 11451, Saudi Arabia \\ Correspondence should be addressed to M. Rafiq H. Siddiqui; rafiqs@ksu.edu.sa
}

Received 14 May 2012; Accepted 28 June 2012

Academic Editor: Stojan Stavber

Copyright (C) 2013 Roushown Ali et al. This is an open access article distributed under the Creative Commons Attribution License, which permits unrestricted use, distribution, and reproduction in any medium, provided the original work is properly cited.

\begin{abstract}
Catalytic activity of copper-manganese mixed oxide nanoparticles $(\mathrm{Cu} / \mathrm{Mn}=1: 2)$ prepared by coprecipitation method has been studied for selective oxidation of benzyl alcohol using molecular oxygen as an oxidizing agent. The copper-manganese $\left(\mathrm{CuMn} \mathrm{n}_{2}\right)$ oxide catalyst exhibited high specific activity of $15.04 \mathrm{mmolg}^{-1} \mathrm{~h}^{-1}$ in oxidation of benzyl alcohol in toluene as solvent. A $100 \%$ conversion of the benzyl alcohol was achieved with $>99 \%$ selectivity to benzaldehyde within a short reaction period at $102^{\circ} \mathrm{C}$. It was found that the catalytic performance is dependent on calcination temperature, and best activity was obtained for the catalyst calcined at $300^{\circ} \mathrm{C}$. The high catalytic performance of the catalyst can be attributed to the formation of active $\mathrm{MnO}_{2}$ phase or absence of less active $\mathrm{Mn}_{2} \mathrm{O}_{3}$ phase in the mixed $\mathrm{CuMn}_{2}$ oxide. The catalyst has been characterized by powder X-ray diffraction (XRD), thermogravimetric analysis (TGA), scanning electron microscopy (SEM), transmission electron microscopy (TEM), Brunauer Emmett-Teller (BET) surface area measurement, and Fourier transform infrared (FT-IR) spectroscopies.
\end{abstract}

\section{Introduction}

Selective oxidation of alcohols to the corresponding aldehyde has been a subject of intense research as these transformations have a significant impact for laboratory synthesis and industrial manufacturing [1-4]. In particular, benzaldehyde is the most desirable as important precursor and intermediates in pharmaceutical and fine organics $[5,6]$. With the increasing environmental concerns, selective oxidation of alcohols to the corresponding aldehydes with environmentally benign inexpensive oxidants, such as molecular oxygen, have attracted great attention from both economic and environmental points of view [7-10]. Many studies have been reported on oxidation of benzyl alcohol to benzaldehyde with molecular oxygen where addition of supports and promoters, visible light irradiation, and process in combination with TEMPO/PINO have been used to improve the catalytic systems [10-17]. A significant number of studies on catalytic oxidation using precious metal or metal-based compounds as catalysts, such $\mathrm{Au}[18,19], \mathrm{Pd}[20,21], \mathrm{Ru}[22,23]$, and $\mathrm{Pt}$ $[24,25]$, have been reported for selective oxidation of benzyl alcohol. These catalysts suffer from high cost and limited availability. Therefore, it is highly desirable to investigate and develop inexpensive catalysts consisting of two $3 \mathrm{~d}$ transition metals because these metals offer environmentally benign and cost-effective alternative to noble metal catalysts.

Whilst numerous studies have been devoted to nonnoble metals or metal-based catalysts, such as $\mathrm{Cu}$ [26], $\mathrm{Ni}$ [27], Fe [28], V [29], Co [30], Ag [31], Cr [32], Mo [33], Zn [34], and Re [35] for oxidation of benzyl alcohol with molecular oxygen, there is renewed interest for searching new transition-metal catalyst with molecular oxygen. Among a series of mixed transition metals, $\mathrm{Mn}$ - and $\mathrm{Cu}$-containing mixed layered double hydroxide [36] and hydrotalcite-like solid [37] exhibited high catalytic activity for oxidation of benzyl alcohol to benzaldehyde. As a consequence, use of various abundant and cheap transition metals like $\mathrm{Cu}$ and $\mathrm{Mn}$-containing compound as catalysts is continuing to inspire research for developing newer and green method for selective oxidation of benzyl alcohol with molecular oxygen. 
An octahedral molecular sieve, a synthetic manganese oxide with a tunnel structure, was reported as a superior catalyst for the aerobic oxidation of alcohols in liquid phase in the presence of molecular oxygen [38]. Catalytic properties of manganese-based octahedral molecular sieves of type KOMS-2 were studied by Fanny Schurz et al. [39, 40] for oxidation of benzyl alcohol with molecular oxygen and reported that the catalyst is superior in activity to that of crystalline $\beta-\mathrm{MnO}_{2}$ and inferior to that of amorphous $\mathrm{MnO}_{2}$. Manganese oxides $\mathrm{MnO}_{x}$ calcined at different temperatures from $110^{\circ}$ to $600^{\circ} \mathrm{C}$ exhibited $100 \%$ selectivity for oxidation of benzyl alcohol to benzaldehyde [41]. The amorphous manganese oxide $\mathrm{MnO}_{x}-110$ possesses higher surface area as well as catalytic activity than those $\mathrm{MnO}_{x}-(200-600)$. Under controlled microwave irradiation, manganese oxide $\alpha-\mathrm{MnO}_{2}$ has been reported [42] to be highly selective catalyst in liquidphase solvent-free oxidation for the oxidation of benzyl alcohol to benzaldehyde with molecular oxygen. Aluminasupported K-Mn mixed oxide [43] showed enhanced catalytic performance for selective oxidation of benzyl alcohol with molecular oxygen. The enhancement of the activity was attributed to the formation of $\alpha-\mathrm{MnO}_{2}$ rather than $\beta-\mathrm{MnO}_{2}$ on coimpregnation of potassium to the $\mathrm{Mn} / \gamma-\mathrm{Al}_{2} \mathrm{O}_{3}$. Highly dispersed manganese oxides supported on activated carbon $(\mathrm{Mn} / \mathrm{AC})[44]$ and alumina $\left(\mathrm{Mn} / \gamma-\mathrm{Al}_{2} \mathrm{O}_{3}\right)$ [45] showed high efficiency for the aerobic oxidation of benzyl alcohol using molecular oxygen. Mn (II) complexes [46] immobilized in the pore channels of mesoporous hexagonal molecular sieves were obtained to be active in catalyzing the oxidation of benzyl alcohols with good conversion percentage and $100 \%$ selectivity using TBHP as the oxidant. $\mathrm{Ru} / \mathrm{MnO}_{x} / \mathrm{CeO}_{2}$ [47] has been reported to have high catalytic activities for oxidation of benzyl alcohols at low temperature $\left(27^{\circ} \mathrm{C}\right)$. Ye et al. [48] developed hexadentate $\mathrm{Q}_{3} \mathrm{Mn}^{\mathrm{III}}$ complexes as efficient catalyst for oxidation of alcohols to the corresponding carbonyl compound using $\mathrm{H}_{2} \mathrm{O}_{2}$.

$\mathrm{Mn}-\mathrm{Ni}$ mixed hydroxide [49] catalyst was found to be efficient in aerobic oxidation of benzyl alcohol with molecular oxygen, where the highest conversion was achieved over $\mathrm{Mn} / \mathrm{Ni}$ molar ration of $6: 4 . \mathrm{Cu}_{x} \mathrm{Mn}_{y}(x=1-5, y=1-4)$ mixed oxides [50] in combination with TEMPO $(2,2,6,6-$ tetramehyl-piperidyl-1-oxyl). Cu-Mn oxide/C (10 wt\%) catalytic system in combination with TEMPO ( $5 \mathrm{~mol} \%$ ) was developed by Yang et al. [51] for oxidation of alcohols with molecular oxygen. Tang et al. [52] reported mixed $\mathrm{Cu}-\mathrm{Mn}$ oxides catalyst supported on alumina for the oxidation of benzyl alcohol using molecular oxygen. They obtained $90.9 \%$ conversion in $4 \mathrm{hrs}$ at $373 \mathrm{~K}$.

Recently, we have reported [53] that copper-manganese oxide with $\mathrm{Cu} / \mathrm{Mn}=1: 4$ has higher catalytic activity than that of $\mathrm{Cu} / \mathrm{Mn}=1: 1$ for the oxidation of benzyl alcohol to benzaldehyde with molecular oxygen. Herein we report further evaluation of the catalytic efficiency and characterization of mixed copper-manganese $\mathrm{CuMn}_{2}$ oxide with $\mathrm{Cu} / \mathrm{Mn}$ molar ratio of $1: 2$. This mixed oxide exhibits excellent catalytic efficiency with specific activity of $15.04 \mathrm{mmolg}^{-1} \mathrm{~h}^{-1}$ and yields 100\% conversions with 99\% selectivity within a short time for selective liquid-phase oxidation of benzyl alcohol to benzaldehyde with molecular oxygen.

\section{Experimental}

2.1. Catalyst Preparation. Copper-manganese oxide solid solution was prepared by a facile precipitation method employing $\mathrm{Cu}\left(\mathrm{NO}_{3}\right)_{2} \cdot 3 \mathrm{H}_{2} \mathrm{O}, \quad \mathrm{Mn}\left(\mathrm{NO}_{3}\right)_{2} \cdot 4 \mathrm{H}_{2} \mathrm{O}$, and $\mathrm{Na}_{2} \mathrm{CO}_{3}$ as described in the literature [53]. All reagents used were analytical grade and purchased from MERCK and $\mathrm{BDH}$ Chemical Ltd. and used without further purification. The powder oxide was calcined at $300^{\circ} \mathrm{C}$ in air for $12 \mathrm{~h}$ and used for oxidation. The catalysts were prepared with the nominal composition of $\mathrm{CuMn}_{2} \mathrm{O}_{4}$, while chemical analyses indicated that the chemical formula of the final product was $\mathrm{CuMn}_{1.87} \mathrm{O}_{4.07}$.

2.2. Techniques Used for Characterization. Scanning electron microscopy (SEM) together with elemental analysis (energy dispersive X-ray analysis: EDX) analysis was conducted on Jeol-SEM model JSM 6360A (Japan). X-ray powder diffraction pattern was recorded on a diffractometer (Rigaku, Ultima IV) at $40 \mathrm{kV}$ and $40 \mathrm{~mA}$ using $\mathrm{Cu}-\mathrm{K}_{\alpha}$ radiation $(\lambda=$ $1.54056 \AA)$ for samples precalcined at $300^{\circ} \mathrm{C}$. Diffraction data were collected from 5 to $70^{\circ}$ with continuous mode, scan speed $2 \mathrm{deg} . / \mathrm{min}$, and sampling width $0.02 \mathrm{deg}$. The surface area was measured using low-temperature nitrogen adsorption by Brunauer-Emmett-Teller (BET) method on a NOVA 4200e surface area and pore size analyzer. Transmission electron microscopy (TEM) was carried out using Jeol TEM model JEM 1101. The infrared spectra were recorded as $\mathrm{KBr}$ pellets using a Parkin-Elmer 1000 FT-IR spectrophotometer. The infrared region of the spectrum recorded was in the region of $4000-400 \mathrm{~cm}^{-1}$. Thermogravimetric analysis (TGA) was carried out using Perkin-Elmer Thermogravimetric analyzer 7. Temperature-programmed oxidation (TPO) and temperature-programmed reduction (TPR) profiles were obtained using Micromeritics Autochem 2 Chemisorption Analyzer (model no. 2920, V4.01). The experiments were carried out under oxygen flow $30(\mathrm{~mL} / \mathrm{min})$ in the temperature range from room temperature to $600^{\circ} \mathrm{C}$ with a heating rate of $10^{\circ} \mathrm{C} / \mathrm{min}$.

2.3. Oxidation Reaction and Product Analysis. The synthesized copper-manganese mixed $\mathrm{CuMn}_{2}$ oxide was tested as catalyst in liquid-phase oxidation of benzyl alcohol using molecular oxygen. The reaction was carried out under atmospheric pressure in a three-necked flask connected with oxygen gas cylinder and condenser. In a typical catalytic experiment, a certain amount of catalyst, $2 \mathrm{mmol}$ benzyl alcohol, and $10 \mathrm{~mL}$ toluene as solvent were added to the flask. The mixture was then heated to $100^{\circ} \mathrm{C}$ using an oil bath. Oxygen was bubbled at a flow rate of $20 \mathrm{~mL} / \mathrm{min}$ into the mixture with continuous stirring using magnetic bar once the reaction temperature was attained. The reaction temperature was maintained at $100-102^{\circ} \mathrm{C}$. A small amount of reaction mixture was collected every $10 \mathrm{~min}$. The collected reaction mixtures were separated by centrifugation, and the liquids were analyzed by gas chromatography (GC) on GC-7890A Agilent Technologies Inc. equipped with a flame ionization detector (FID) and a 19019S-001 HP-PONA column. The 


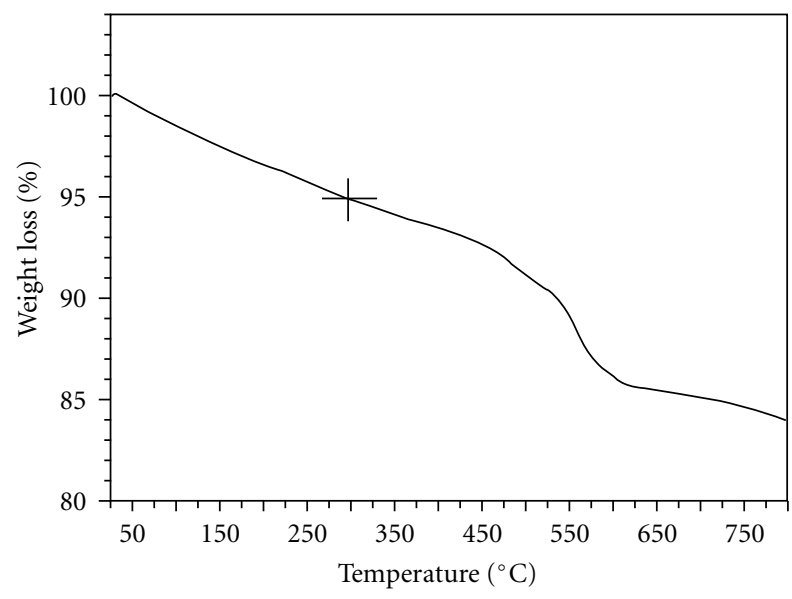

Figure 1: TGA profile of mixed $\mathrm{CuMn}_{2}$ oxide.

conversion of benzyl alcohol and the selectivity to benzaldehyde were calculated by the peak area.

\section{Results and Discussion}

\subsection{Characterization of Mixed $\mathrm{CuMn} n_{2}$ Oxide Catalyst}

The morphology of the catalysts was studied with a combination of various characterization techniques. The thermal stability of $\mathrm{CuMn}_{2}$ oxide determined by thermogravimetric analysis (TGA) is shown in Figure 1. TGA curve of the catalyst shows no significant weight loss up to $300^{\circ} \mathrm{C}$, suggesting thermal stability of the compound up to $300^{\circ} \mathrm{C}$. The loss of wt $\%$ in the temperature $25-300^{\circ} \mathrm{C}$ is observed to be $5 \%$ which is due to removal of surface-absorbed water or bound water in the structure of the oxide. The presence of water in the catalyst was also detected by IR spectroscopy. The noticeable step of thermal decomposition is observed between $425^{\circ}$ and $625^{\circ} \mathrm{C}$ with a loss of wt.\% 7.6. This loss of wt. in this temperature range may be due to decomposition of one or more existing phases and/or formation of $\mathrm{Mn}_{2} \mathrm{O}_{3}$ phase. The total loss of weight was observed to be $16.08 \%$ when the catalyst was heated up to $800^{\circ} \mathrm{C}$. It can be concluded that the catalyst is thermally stable up to $>300^{\circ} \mathrm{C}$.

$\mathrm{X}$-ray diffraction pattern (Figure 2) of the mixed $\mathrm{CuMn}_{2}$ oxide precalcined at $300^{\circ} \mathrm{C}$ shows a mixture of three phases with cubic $\mathrm{CuMn}_{2} \mathrm{O}_{4}$ (ICSD no. 93434), hexagonal $\mathrm{MnO}_{2}$ (ICSD no. 76430), and monoclinic $\mathrm{CuO}$ (ICSD no. 92368). Peaks of the corresponding phases are indicated by different symbols in Figure 2. Some peaks of cubic $\mathrm{CuMn}_{2} \mathrm{O}_{4}$ phase are not apparent, but an influence in peak intensity/width of coexisting phase can be detected. The less visible peaks can be attributed to the formation of very little amount of $\mathrm{CuMn}_{2} \mathrm{O}_{4}$ phase. These peaks might be clearly visible with diffraction pattern having higher resolution and strong intensity, like synchrotron X-ray diffraction pattern. $\mathrm{Mn}_{2} \mathrm{O}_{3}$ and $\mathrm{MnCO}_{3}$ phases, which were detected in our earlier studies [53] in $\mathrm{CuMn}_{4} \mathrm{O}_{4}(\mathrm{Cu}: \mathrm{Mn}=1: 4)$, were not detected in the present sample by X-ray diffraction. It is seen in the diffraction

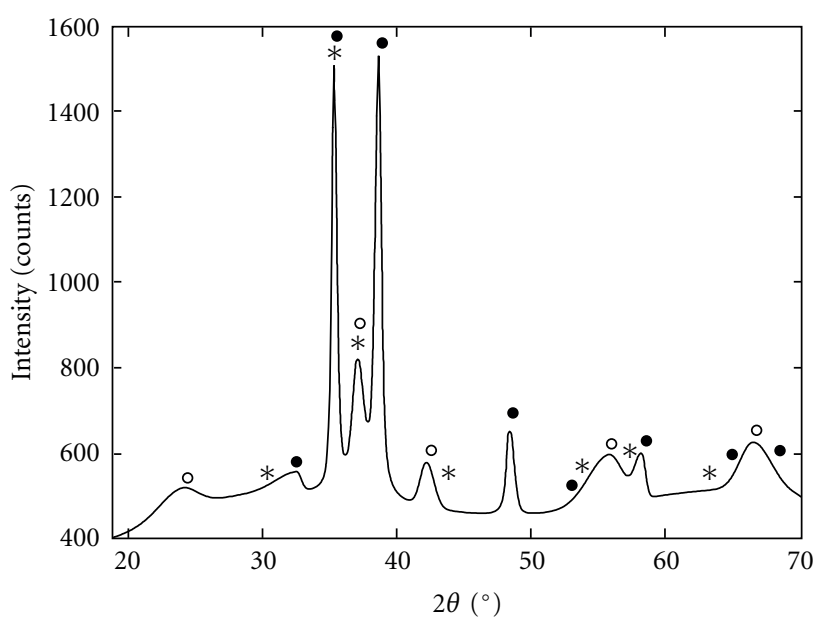

$$
\begin{aligned}
& * \mathrm{CuMn}_{2} \mathrm{O}_{4} \\
& \text { - } \mathrm{CuO} \\
& \text { - } \mathrm{MnO}_{2}
\end{aligned}
$$

Figure 2: Powder X-ray diffraction pattern of mixed $\mathrm{CuMn}_{2}$ oxide. Each symbol indicates peak of the corresponding phases.

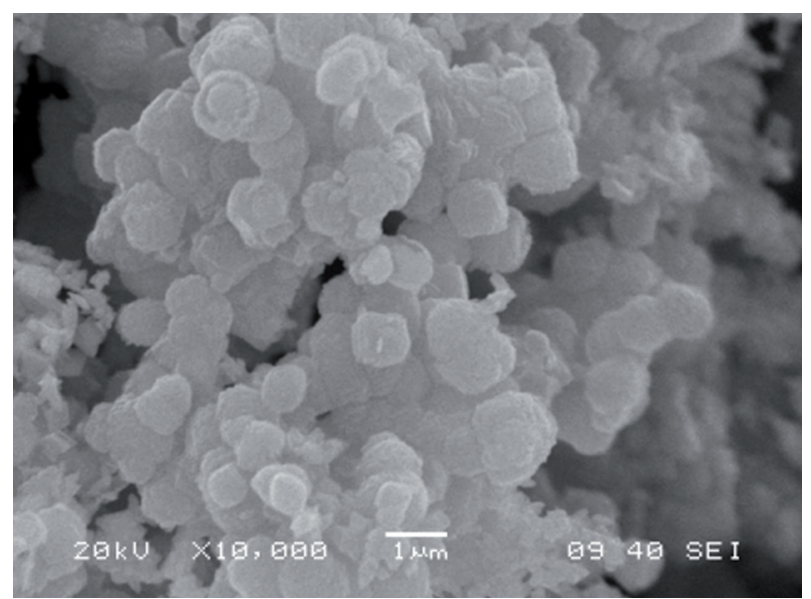

FIGURE 3: Scanning electron microscopy (SEM) image of mixed $\mathrm{CuMn}_{2}$ oxide precalcined at $300^{\circ} \mathrm{C}$.

pattern that peaks of $\mathrm{MnO}_{2}$ are broader, suggesting an amorphous nature of this phase. The crystallite size of the catalysts was determined from XRD line broadening (determined using the Scherrer equation) using peaks appeared at 35.62, $37.40,38.88,42.47$, and 48.69 in $2 \theta$ since these seem to be single peak. Furthermore, better result is often obtained using single peak, and peaks appeared between 30 and $50^{\circ}$ in $2 \theta$. The average crystallite size was obtained to be $29.26 \mathrm{~nm}$ by averaging the size obtained from the five peaks. The higher specific activity of the catalyst may be attributed to the formation of amorphous $\mathrm{MnO}_{2}$ and/or small crystallite size of the mixed oxide.

Figure 3 shows images of scanning electron microscopy (SEM) of the mixed $\mathrm{CuMn}_{2}$ oxide after calcinations at $300^{\circ} \mathrm{C}$. A uniform spherical morphology with the average diameter being ca $900 \mathrm{~nm}$ was observed. The surface area of the mixed 


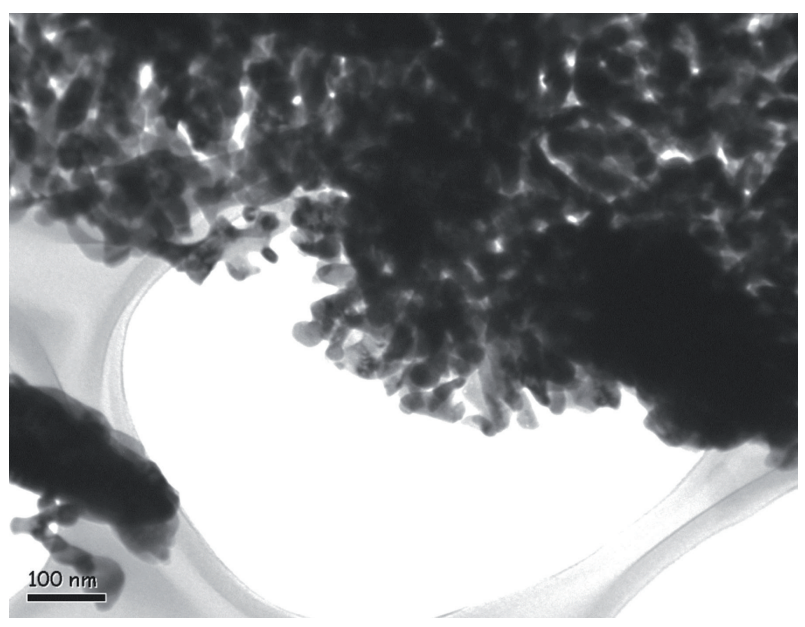

Figure 4: Transmission electron microscopy (TEM) image of mixed $\mathrm{CuMn}_{2}$ oxide precalcined at $300^{\circ} \mathrm{C}$.

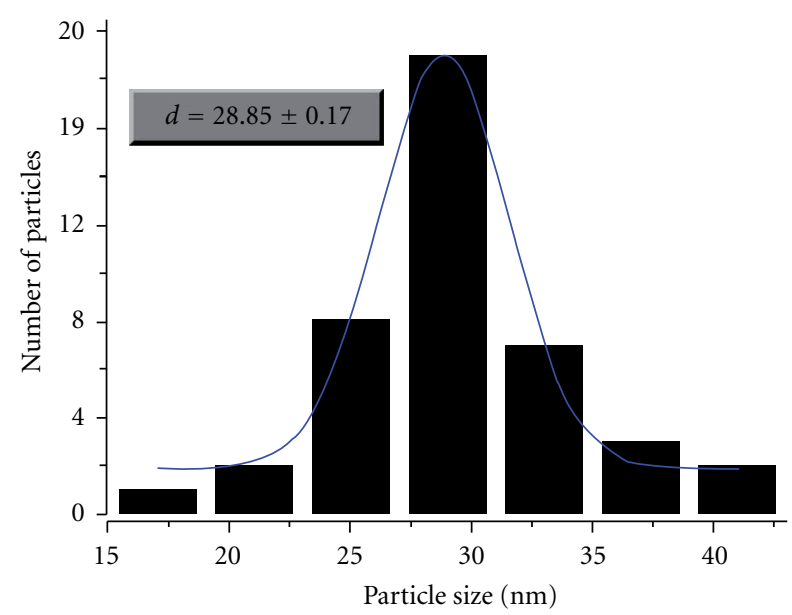

FIGURE 5: Particle size distribution determined from TEM images of mixed $\mathrm{CuMn}_{2}$ oxide precalcined at $300^{\circ} \mathrm{C}$.

$\mathrm{CuMn}_{2}$ oxide was obtained to be $101.86 \mathrm{~m}^{2} / \mathrm{g}$ through BET analysis.

TEM images of the catalyst (Figure 4) showed no indication of the existence of a unique phase and are not well crystalline. Copper and manganese oxides as well as other species were distributed over all the area.

Particle size distribution calculated from the TEM image (Figure 4) using ImageJ 1.44 [54] is shown in Figure 5. Mean particle size was obtained to be $28.85 \pm 0.17 \mathrm{~nm}$, which is in good agreement with the crystallite size determined by Scherrer equation using XRD line broadening $(29.26 \mathrm{~nm})$.

In Figure 6, FT-IR spectrum of the mixed $\mathrm{CuMn}_{2}$ oxide is shown. The IR band appearing at $3431 \mathrm{~cm}^{-1}$ may be due to the presence of $\mathrm{OH}$ group and $\mathrm{H}_{2} \mathrm{O}$ as bound water in the structure. The absorption band at $1636 \mathrm{~cm}^{-1}$ corresponds to bending vibration modes of combined water molecules. The presence of absorption band at 582 and $536 \mathrm{~cm}^{-1}$ may be assigned to vibration of $\mathrm{Cu}-\mathrm{O}$ in monoclinic $\mathrm{CuO}$. Morales et al. [55] observed similar bands in copper-manganese

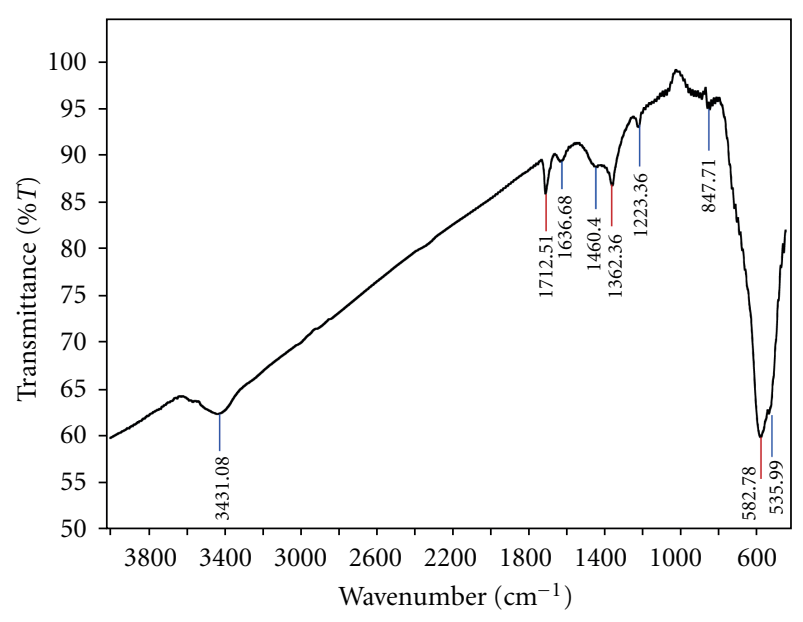

FIGURE 6: Fourier transform infrared (FTIR) spectroscopy of mixed $\mathrm{Cu}-\mathrm{Mn}$ oxide $(\mathrm{Cu}: \mathrm{Mn}=1: 2)$ precalcined at $300^{\circ} \mathrm{C}$.

mixed oxide. Peaks appearing in the range $1223-1713 \mathrm{~cm}^{-1}$ may be resulting from interactions among $\mathrm{Mn}, \mathrm{OH}$, and $\mathrm{O}$ atoms/groups. The characteristic bands at ca 672 and $524 \mathrm{~cm}^{-1}$ for $\mathrm{Mn}_{2} \mathrm{O}_{3}$ [56] were not observed, suggesting the absence of $\mathrm{Mn}_{2} \mathrm{O}_{3}$ phase which is in agreement with the Xray diffraction pattern.

The TPR profile of the oxide exhibited a large peak centered at $220^{\circ} \mathrm{C}$, which may be attributed to the reduction of $\mathrm{CuO}$ as $\mathrm{X}$-ray diffraction pattern showed the presence of this phase. This reduction stage was detected for $\mathrm{Cu}_{1} \mathrm{Mn}_{2}$ oxide [57]. Another weak peak that appeared around $400^{\circ} \mathrm{C}$ may be reduction from $\mathrm{MnO}_{2}$ to $\mathrm{Mn}_{2} \mathrm{O}_{3}$. TPO profile showed two weak and broad peaks centered at $180^{\circ}$ and $300^{\circ} \mathrm{C}$. These two stages can be ascribed to the oxidation from $\mathrm{MnO}$ to $\mathrm{MnO}_{2}$ via $\mathrm{Mn}_{3} \mathrm{O}_{4}$. Soylu et al. [57] reported similar oxidation stages in $9.5 \% \mathrm{MnO}_{2} / \mathrm{HCLT}$.

3.2. Catalytic Performance. The mixed $\mathrm{CuMn}_{2}$ oxide nanoparticles were synthesized following method described in our previous work [53]. Initially, we examined the effect of calcined temperature at $300^{\circ} \mathrm{C}$ and $500^{\circ} \mathrm{C}$ on catalytic performance of mixed $\mathrm{CuMn}_{2}$ oxide and found that catalyst precalcined at $300^{\circ} \mathrm{C}$ led to higher performance in liquidphase selective oxidation of benzyl alcohol with molecular oxygen. In order to determine the effect of catalyst concentration on activity, $300 \mathrm{mg}$ of the mixed $\mathrm{CuMn}_{2}$ oxide was used as catalyst for $2 \mathrm{mmol}$ of benzyl alcohol. A $100 \%$ conversion of benzyl alcohol was obtained within a very short reaction time $(<10 \mathrm{~min})$ at $102^{\circ} \mathrm{C}$. Benzyl alcohol was converted into benzaldehyde with $100 \%$ conversion at $102^{\circ} \mathrm{C}$ after $20 \mathrm{~min}$ in presence of $200 \mathrm{mg}$ catalyst with molecular oxygen. The specific activity for this conversion was determined to be $30.00 \mathrm{mmolg}^{-1} \mathrm{~h}^{-1}$. A longer reaction time $(80 \mathrm{~min})$ was required to achieve $100 \%$ conversion under the same reaction conditions in presence of $100 \mathrm{mg}$ catalyst. The specific activity obtained using $100 \mathrm{mg}$ of the catalyst was determined to be $15.00 \mathrm{mmolg}^{-1} \mathrm{~h}^{-1}$. With decreasing the amount of catalyst from $200 \mathrm{mg}$ to $100 \mathrm{mg}$, the specific activity decreased by half to obtain $100 \%$ with no change in selectivity to benzaldehyde. 
TABLE 1: Catalytic performance in oxidation of benzyl alcohol to benzaldehyde over mixed $\mathrm{CuMn}_{2}$ oxide using molecular oxygen.

\begin{tabular}{|c|c|c|c|c|}
\hline Catalyst (mg) & Time (min) & Conversion of alcohol (\%) & Specific activity $\left(\mathrm{mmol} \cdot \mathrm{g}^{-1} \cdot \mathrm{h}^{-1}\right)$ & Selectivity (\%) \\
\hline \multirow{2}{*}{200} & 10 & 85.40 & 51.24 & 99 \\
\hline & 20 & 100 & 30.00 & 99 \\
\hline \multirow{8}{*}{100} & 10 & 49.02 & 58.82 & 99 \\
\hline & 20 & 69.20 & 41.52 & 99 \\
\hline & 30 & 81.00 & 32.40 & 99 \\
\hline & 40 & 87.74 & 26.32 & 99 \\
\hline & 50 & 92.37 & 22.17 & 99 \\
\hline & 60 & 95.81 & 19.16 & 99 \\
\hline & 70 & 98.17 & 16.83 & 99 \\
\hline & 80 & 100 & 15.00 & 99 \\
\hline
\end{tabular}

Reaction conditions: $100 \mathrm{mg}$ catalyst, $2 \mathrm{mmol}$ benzyl alcohol in $10 \mathrm{~mL}$ toluene, and reaction temperature $102^{\circ} \mathrm{C}$.

TABLE 2: Comparison of Mn-based catalyst with earlier reported results for its catalytic performance in oxidation of benzyl alcohol to benzaldehyde.

\begin{tabular}{|c|c|c|c|c|c|}
\hline Catalyst & Conversion (\%) & Selectivity (\%) & Temp. $\left({ }^{\circ} \mathrm{C}\right)$ & Specific activity $\left(\mathrm{mmol} \cdot \mathrm{g}^{-1} \cdot \mathrm{h}^{-1}\right)$ & Reference \\
\hline $\mathrm{MnO}_{2}$ & 37.7 & 98.6 & 80 & 48.51 & {$[42]$} \\
\hline $\mathrm{Cu}-\mathrm{Mn}$ oxide/C and TEMPO & 100 & $>99$ & 80 & 15.47 & {$[51]$} \\
\hline $\mathrm{Cu}_{2} \mathrm{Mn}$-TEMPO & 98.8 & 98.3 & 120 & 15.28 & {$[50]$} \\
\hline $\mathrm{CuMn}_{2}$ oxide & 100 & 99 & 102 & 15.00 & This work \\
\hline $\mathrm{Mn}-\mathrm{Cu}$-TEMPO & 98.0 & 98.0 & 20 & 13.37 & {$[58]$} \\
\hline $\mathrm{Mn}-\mathrm{Fe}-\mathrm{HD}$ & 53.9 & 70.6 & 94 & 11.21 & {$[36]$} \\
\hline $\mathrm{Ru} / \mathrm{MnO}_{x} / \mathrm{CeO}_{2}$ & $>99.0$ & $>99$ & 40 & 9.80 & {$[47]$} \\
\hline Amorphous $\mathrm{MnO}_{x}-110$ & 72.7 & 100 & 110 & 9.69 & {$[41]$} \\
\hline$\left[\mathrm{Mn}(\mathrm{bpy})_{2}\right]^{2+} / \mathrm{HMS}$ & 49.2 & 100 & 50 & 9.23 & {$[46]$} \\
\hline $\mathrm{Mn}_{6} \mathrm{Ni}_{4}$ hydroxide & 89.0 & 99 & 100 & 8.90 & {$[49]$} \\
\hline $\mathrm{CuMn}_{4}$ oxide & 99 & 95 & 102 & 8.49 & {$[53]$} \\
\hline $\mathrm{Mn}-\mathrm{Cr}-\mathrm{HT}$ & 18.7 & 99.5 & 210 & 7.23 & {$[37]$} \\
\hline H-K-OMS-2 & 97.0 & 100 & 110 & 4.85 & {$[40]$} \\
\hline K-OMS-2 & 72.0 & 100 & 110 & 3.38 & [39] \\
\hline $\mathrm{K}(1) \mathrm{Mn}(1) / \gamma-\mathrm{Al}_{2} \mathrm{O}_{3}$ & 72.9 & $>99$ & 100 & 2.43 & {$[43]$} \\
\hline $\mathrm{Mn}(1) / \gamma-\mathrm{Al}_{2} \mathrm{O}_{3}-p$ & 93.0 & $>99$ & 100 & 2.33 & {$[45]$} \\
\hline $\mathrm{K}(2) \mathrm{Mn}(1) / \mathrm{C}$ & 99.0 & $>99$ & 100 & 1.65 & [59] \\
\hline $\mathrm{Cu}_{1} \mathrm{Mn}_{4} / \mathrm{Al}_{2} \mathrm{O}_{3}$ & 90.9 & $>99$ & 100 & 1.52 & {$[52]$} \\
\hline 10 wt.\%Mn/AC & 42.5 & $>99$ & 100 & 1.06 & {$[44]$} \\
\hline $\mathrm{MnCl}_{2} /$ Montmorillonite-K10 & 99.0 & 100 & 60 & 0.20 & {$[60]$} \\
\hline
\end{tabular}

The selectivity for the oxidation of alcohol to aldehyde was obtained to be $>99 \%$ for all reactions. It should be noted that, in the absence of catalyst, no detectable conversion of benzyl alcohol was obtained. Also, blank experiment carried out over the catalyst with only solvent toluene (without benzyl alcohol) showed no formation of aldehyde under the same reaction conditions. The conversion of benzyl alcohol, specific activity, and selectivity obtained over the catalyst are mentioned in Table 1 and Figure 7. The initial specific activity gradually decreased, as the catalyst deactivated with reaction time.

The specific activities obtained over the mixed $\mathrm{CuMn}_{2}$ oxide are about two times higher compared with that of $\mathrm{CuMn}_{4} \mathrm{O}_{4}$ reported in our earlier study [53]. The mixed $\mathrm{CuMn}_{4}(\mathrm{Cu}: \mathrm{Mn}=1: 4)$ oxide precalcined at $300^{\circ} \mathrm{C}$ formed mainly $\mathrm{MnCO}_{3}$ and $\mathrm{CuO}$ phases, whereas a minor $\mathrm{CuMn}_{2} \mathrm{O}_{4}$ phase was detected. On the contrary, mixed $\mathrm{CuMn}_{2}$ oxide was composed of hexagonal $\mathrm{MnO}_{2}$ and monoclinic $\mathrm{CuO}$ with a minor cubic $\mathrm{CuMn}_{2} \mathrm{O}_{4}$ phases. Therefore, the higher catalytic activity for $\mathrm{CuMn}_{2}$ oxide can be attributed to the formation of amorphous $\mathrm{MnO}_{2}$ phase which was not formed in $\mathrm{CuMn}_{4}$ oxide. The catalytic activity for $\mathrm{CuMn}_{2}$ oxide may be enhanced by the active $\mathrm{MnO}_{2}$ phase. The absence of $\mathrm{MnCO}_{3}$ phase in mixed $\mathrm{CuMn}_{2}$ oxide which was present in $\mathrm{CuMn}_{4}$ oxide may also result in higher activity.

The performance in terms of specific activity of mixed $\mathrm{CuMn}_{2}$ oxide catalyst is compared (Table 2) with those of the Mn-based heterogeneous catalysts reported earlier in oxidation of benzyl alcohol to benzaldehyde. It is seen that Yang et al. [42] reported solvent-free oxidation of 


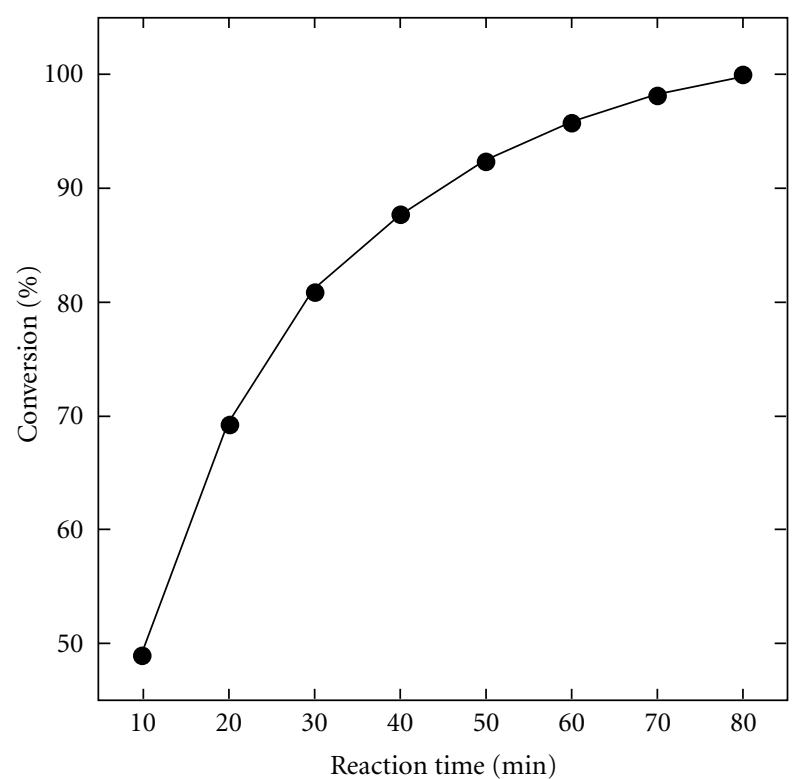

Figure 7: Oxidation of benzyl alcohol to benzaldehyde over mixed $\mathrm{CuMn}_{2}$ oxide precalcined at $300^{\circ} \mathrm{C}$. (100 $\mathrm{mg}$ catalyst, $2 \mathrm{mmol}$ benzyl alcohol in $10 \mathrm{~mL}$ toluene, and reaction temperature $102^{\circ} \mathrm{C}$ ).

benzyl alcohol to benzaldehyde under controlled microwave irradiation manganese oxide $\mathrm{MnO}_{2}$ having the highest specific activity $48.51\left(\mathrm{mmolg}^{-1} \mathrm{~h}^{-1}\right)$. This specific activity $\left(48.51 \mathrm{mmolg}^{-1} \mathrm{~h}^{-1}\right.$ ) was obtained with $37.7 \%$ conversion after $3 \mathrm{~h}$, which is less compared to the specific activity $58.82\left(\mathrm{mmolg}^{-1} \mathrm{~h}^{-1}\right)$ obtained with $49.02 \%$ conversion after $10 \mathrm{~min}$ in the present study (Table 1). It can be considered that when $\mathrm{MnO}_{2}$ coexists in $\mathrm{CuMn}_{2}$ oxide it showed higher catalytic activity than that of pure $\mathrm{MnO}_{2}$. This higher activity can be attributed to the synergic effect between $\mathrm{MnO}_{2}$ and mixed $\mathrm{CuMn}_{2}$ oxide.

The mixed $\mathrm{CuMn}_{2}$ oxide provided the specific activity at a complete conversion $(100 \%)$ is almost the same as that catalyzed by TEMPO-supported $\mathrm{Cu}_{2} \mathrm{Mn}$ oxide [50] at $98.8 \%$ conversion. The specific catalytic activity $\left(15.00 \mathrm{mmolg}^{-1} \mathrm{~h}^{-1}\right)$ of the mixed $\mathrm{CuMn}_{2}$ oxide is comparable with that of $\mathrm{C}-(10 \mathrm{wt} \%)$ and TEMPO-(5 mol\%) supported $\mathrm{Cu}-\mathrm{Mn}$ oxide [51] $\left(15.47 \mathrm{mmolg}^{-1} \mathrm{~h}^{-1}\right)$ at a complete conversion (100\%). Among all other Mn-based catalysts listed in Table 2, the mixed $\mathrm{CuMn}_{2}$ oxide prepared by facile method showed excellent catalytic activity without any support/influence of TEMPO, C, HT, or others (Table 1) at a complete conversion (100\%) of benzyl alcohol.

\section{Conclusions}

The mixed $\mathrm{CuMn}_{2}$ oxide nanoparticles prepared by a facile coprecipitation method were found to exhibit excellent catalytic activity and selectivity for oxidation of benzyl alcohol to benzaldehyde using molecular oxygen. The mixed $\mathrm{CuMn}_{2}$ oxide precalcined at $300^{\circ} \mathrm{C}$ showed high specific activity of $15.04 \mathrm{mmolg}^{-1} \mathrm{~h}^{-1}$ with a complete conversion $(100 \%)$ of benzyl alcohol and 99\% selectivity to benzaldehyde within a short reaction period. The X-ray diffraction pattern of the mixed $\mathrm{CuMn}_{2}$ oxide precalcined at $300^{\circ} \mathrm{C}$ indicated that the compound is composed of a mixture of hexagonal $\mathrm{MnO}_{2}$ and monoclinic $\mathrm{CuO}$ phases including a minor cubic $\mathrm{CuMn}_{2} \mathrm{O}_{4}$ phase. The excellent catalytic activity of this mixed oxide can be attributed to the formation of active amorphous $\mathrm{MnO}_{2}$ phase. Absence of less active $\mathrm{Mn}_{2} \mathrm{O}_{3}$ and/or $\mathrm{MnCO}_{3}$ phases in mixed $\mathrm{CuMn}_{2}$ oxide can be considered as another reason for its higher activity.

\section{Acknowledgment}

This work is supported by the Research Center, College of Science, King Saud University, Riyadh, Saudi Arabia.

\section{References}

[1] D. Lenoir, "Selective oxidation of organic compounds-sustainable catalytic reactions with oxygen and without transition metals?" Angewandte Chemie, vol. 45, no. 20, pp. 3206-3210, 2006.

[2] G. Tojo and M. Fernandez, Oxidation of Alcohols to Aldehydes and Ketones: A Guide to Current Common Practice, Springer, New York, NY, USA, 2006, Edited by: G. Tojo.

[3] T. Matsumoto, M. Ueno, N. Wang, and S. Kobayashi, "Recent advances in immobilized metal catalysts for environmentally benign oxidation of alcohols," Chemistry, vol. 3, no. 2, pp. 196-214, 2008.

[4] J. Fan, Y. Dai, Y. Li et al., "Low-temperature, highly selective, gas-phase oxidation of benzyl alcohol over mesoporous K$\mathrm{Cu}-\mathrm{TiO}_{2}$ with stable copper(I) oxidation state," Journal of the American Chemical Society, vol. 131, no. 43, pp. 15568-15569, 2009.

[5] R. Yamamoto, Y. S. Sawayama, H. Shibahara, Y. Ichihashi, S. Nishiyama, and S. Tsuruya, "Promoted partial oxidation activity of supported Ag catalysts in the gas-phase catalytic oxidation of benzyl alcohol," Journal of Catalysis, vol. 234, no. 2, pp. 308-317, 2005.

[6] C. D. Pina, E. Falletta, and M. Rossi, "Highly selective oxidation of benzyl alcohol to benzaldehyde catalyzed by bimetallic gold-copper catalyst," Journal of Catalysis, vol. 260, no. 2, pp. 384-386, 2008.

[7] U. R. Pillai and E. S. Demessie, "Selective oxidation of alcohols by molecular oxygen over a $\mathrm{Pd} / \mathrm{MgO}$ catalyst in the absence of any additives," Green Chemistry, vol. 6, no. 3, pp. 161-165, 2004.

[8] B. Z. Zhan and A. Thompson, "Recent developments in the aerobic oxidation of alcohols," Tetrahedron, vol. 60, no. 13, pp. 2917-2935, 2004.

[9] J. E. Backvall, Ed., Modern Oxidation Methods, Wiley-VCH, 2004.

[10] T. Mallat and A. Baiker, "Oxidation of alcohols with molecular oxygen on solid catalysts," Chemical Reviews, vol. 104, no. 6, pp. 3037-3058, 2004.

[11] M. S. Sigman and D. R. Jensen, "Ligand-modulated palladiumcatalyzed aerobic alcohol oxidations," Accounts of Chemical Research, vol. 39, no. 3, pp. 221-229, 2006.

[12] I. C. W. E. Arends, R. A. Sheldon, and J. E. Bäckvall, Eds., Modern Oxidation Methods, Wiley-VCH, Weinham, Germany, 2004. 
[13] I. Laszlo and Simandi, Advances in Catalytic Activation of Dioxygen by Metal Complexes, Kluwer Academic Publishers, Dordrecht, The Netherlands, 2004.

[14] M. Francesco, P. Carlo, R. Francesco, F. Francesca, and F. P. Gian, "A new, highly selective synthesis of aromatic aldehydes by aerobic free-radical oxidation of benzylic alcohols, catalysed by $n$-hydroxyphthalimide under mild conditions. Polar and enthalpic effects," Chemical Communications, no. 7, pp. 688-689, 2002.

[15] M. Francesco, R. Francesco, C. Andrea et al., "Mechanisms of the aerobic oxidation of alcohols to aldehydes and ketones, catalysed under mild conditions by persistent and nonpersistent nitroxyl radicals and transition metal salts-polar, enthalpic, and captodative effects," European Journal of Organic Chemistry, vol. 2004, no. 1, pp. 109-119, 2004.

[16] U. Muhmmet, F. Ryota, and I. Kazuaki, "Bromine-catalyzed aerobic oxidation of alcohols," Chemistry, vol. 5, no. 3, pp. 456-460, 2010.

[17] N. Hiroki and I. Akichika, "Aerobic oxidation of benzyl- and allylic alcohols under visible light irradiation of a fluorescent lamp in the presence of catalytic iodine," Chemical \& Pharmaceutical Bulletin, vol. 54, no. 11, pp. 1620-1621, 2006.

[18] L. C. Wang, L. He, Q. Liu et al., "Solvent-free selective oxidation of alcohols by molecular oxygen over gold nanoparticles supported on $\beta-\mathrm{MnO}_{2}$ nanorods," Applied Catalysis A, vol. 344, no. 1-2, pp. 150-157, 2008.

[19] V. R. Choudhary and D. K. Dumbre, "Solvent-free selective oxidation of benzyl alcohol to benzaldehyde by tertbutyl hydroperoxide over $\mathrm{U}_{3} \mathrm{O}_{8}$-supported nano-gold catalysts," Applied Catalysis A, vol. 375, no. 2, pp. 252-257, 2010.

[20] Y. Chen, H. Zheng, Z. Guo et al., "Pd catalysts supported on $\mathrm{MnCeO}_{x}$ mixed oxides and their catalytic application in solvent-free aerobic oxidation of benzyl alcohol: support composition and structure sensitivity," Journal of Catalysis, vol. 283, no. 1, pp. 34-44, 2011.

[21] Z. Hai, L. Ying, and Z. Xungao, "Selective oxidation of benzyl alcohol catalyzed by palladium nanoparticles supported on carbon-coated iron nanocrystals," Chinese Journal of Catalysis, vol. 32, no. 11-12, pp. 1693-1701, 2011.

[22] T. Yasu-eda, S. Kitamura, N. O. Ikenaga, T. Miyake, and T. Suzuki, "Selective oxidation of alcohols with molecular oxygen over $\mathrm{Ru} / \mathrm{CaO}-\mathrm{ZrO}_{2}$ catalyst," Journal of Molecular Catalysis A, vol. 323, no. 1-2, pp. 7-15, 2010.

[23] H. Yu, Y. Zhang, X. Fu, F. Peng, H. Wang, and J. Yang, "Deactivation and regeneration of $\mathrm{RuO}_{2} \cdot x \mathrm{H}_{2} \mathrm{O} / \mathrm{CNT}$ catalyst for aerobic oxidation of benzyl alcohol," Catalysis Communications, vol. 10, no. 13, pp. 1752-1756, 2009.

[24] Y. M. A. Yamada, T. Arakawa, H. Hocke, and Y. Uozumi, "A nanoplatinum catalyst for aerobic oxidation of alcohols in water," Angewandte Chemie, vol. 46, no. 5, pp. 704-706, 2007.

[25] T. Mallat and A. Baiker, "Oxidation of alcohols with molecular oxygen on platinum metal catalysts in aqueous solutions," Catalysis Today, vol. 19, no. 2, pp. 247-283, 1994.

[26] Y. Perez, R. Ballesteros, M. Fajardo, I. Sierra, and I. D. Hierro, "Copper-containing catalysts for solvent-free selective oxidation of benzyl alcohol," Journal of Molecular Catalysis A, vol. 352, pp. 45-56, 2012.

[27] S. R. Ali, P. Chandra, M. Latwal, S. K. Jain, V. K. Bansal, and S. P. Singh, "Synthesis of Nickel hexacyanoferrate nanoparticles and their potential as heterogeneous catalysts for the solventfree oxidation of benzyl alcohol," Chinese Journal of Catalysis, vol. 32, no. 11-12, pp. 1844-1849, 2011.
[28] R. Naik, A. Nizam, A. Siddekha, and M. A. Pasha, "An efficient sonochemical oxidation of benzyl alcohols into benzaldehydes by $\mathrm{FeCl}_{3} / \mathrm{HNO}_{3}$ in acetone," Ultrasonics Sonochemistry, vol. 18, no. 5, pp. 1124-1127, 2011.

[29] G. C. Behera and K. M. Parida, "Liquid phase catalytic oxidation of benzyl alcohol to benzaldehyde over vanadium phosphate catalyst," Applied Catalysis A, vol. 413-414, pp. 245-253, 2012.

[30] S. M. Seyedi, R. Sandaroos, and G. H. Zohuri, "Novel cobalt(II) complexes of amino acids-Schiff bases catalyzed aerobic oxidation of various alcohols to ketones and aldehyde," Chinese Chemical Letters, vol. 21, no. 11, pp. 1303-1306, 2010.

[31] M. Deng, G. Zhao, Q. Xue, L. Chen, and Y. Lu, "Microfibrousstructured silver catalyst for low-temperature gas-phase selective oxidation of benzyl alcohol," Applied Catalysis B, vol. 99, no. 1-2, pp. 222-228, 2010.

[32] O. F. Ozturk, B. Z. Karan, and S. Karabulut, "Solvent-free oxidation of benzyl alcohol over chromium orthoborate," Catalysis Communications, vol. 9, no. 7, pp. 1644-1648, 2008.

[33] P. S. N. Rao, K. T. V. Rao, P. S. Saiprasad, and N. Lingaiah, “The role of vanadia for the selective oxidation of benzyl alcohol over heteropolymolybdate supported on alumina," Chinese Journal of Catalysis, vol. 32, no. 11-12, pp. 1719-1726, 2011.

[34] S. R. Ali, V. K. Bansal, A. A. Khan, S. K. Jain, and M. A. Ansari, "Growth of zinc hexacyanoferrate nanocubes and their potential as heterogeneous catalyst for solvent-free oxidation of benzyl alcohol," Journal of Molecular Catalysis A, vol. 303, no. 1-2, pp. 60-64, 2009.

[35] P. Paraskevopoulou, N. Psaroudakis, S. Koinis, P. Stavropoulos, and K. Mertis, "Catalytic selective oxidation of benzyl alcohols to aldehydes with rhenium complexes," Journal of Molecular Catalysis A, vol. 240, no. 1-2, pp. 27-32, 2005.

[36] V. R. Choudhary, D. K. Dumbre, B. S. Uphade, and V. S. Narkhede, "Solvent-free oxidation of benzyl alcohol to benzaldehyde by tert-butyl hydroperoxide using transition metal containing layered double hydroxides and/or mixed hydroxides," Journal of Molecular Catalysis A, vol. 215, no. 1-2, pp. 129-135, 2004.

[37] V. R. Choudhary, P. A. Chaudhari, and V. S. Narkhede, "Solventfree liquid phase oxidation of benzyl alcohol to benzaldehyde by molecular oxygen using non-noble transition metal containing hydrotalcite-like solid catalysts," Catalysis Communications, vol. 4, no. 4, pp. 171-175, 2003.

[38] S. L. Suib, "Porous manganese oxide octahedral molecular sieves and octahedral layered materials," Accounts of Chemical Research, vol. 41, no. 4, pp. 479-487, 2008.

[39] F. Schurz, J. M. Bauchert, T. Merker, T. Schleid, H. Hasse, and R. Glaser, "Octahedral molecular sieves of the type K-OMS-2 with different particle sizes and morphologies: Impact on the catalytic properties in the aerobic partial oxidation of benzyl alcohol," Applied Catalysis A, vol. 355, no. 1-2, pp. 42-49, 2009.

[40] Y. C. Son, V. D. Makwana, A. R. Howell, and S. L. Suib, "Efficient, catalytic, aerobic oxidation of alcohols with octahedral molecular sieves," Angewandte Chemie, vol. 40, no. 22, pp. 4280-4283, 2001.

[41] H. Jing, S. Keqiang, H. Daiping, and X. Boqing, "Amorphous manganese oxide for catalytic aerobic oxidation of benzyl alcohol," Chinese Journal of Catalysis, vol. 28, no. 12, pp. 1025-1027, 2007.

[42] S. Yang, L. Wang, Y. Liu, Y. Cao, H. Y. He, and K. N. Fan, "Microwave-accelerated solvent-free aerobic oxidation of benzyl alcohol over efficient and reusable manganese oxides," Catalysis Communications, vol. 8, no. 12, pp. 2181-2185, 2007. 
[43] Q. Tang, X. Huang, C. Wu, P. Zhao, Y. Chen, and Y. Yang, "Structure and catalytic properties of K-doped manganese oxide supported on alumina," Journal of Molecular Catalysis A, vol. 306, no. 1-2, pp. 48-53, 2009.

[44] Q. Tang, X. Huang, Y. Chen, T. Liu, and Y. Yang, "Characterization and catalytic application of highly dispersed manganese oxides supported on activated carbon," Journal of Molecular Catalysis A, vol. 301, no. 1-2, pp. 24-30, 2009.

[45] Q. Tang, X. Gong, C. Wu, Y. Chen, A. Borgna, and Y. Yang, "Insights into the nature of alumina-supported $\mathrm{MnOOH}$ and its catalytic performance in the aerobic oxidation of benzyl alcohol," Catalysis Communications, vol. 10, no. 7, pp. 1122-1126, 2009.

[46] V. Mahdavi, M. Mardani, and M. Malekhosseini, "Oxidation of alcohols with tert-butylhydroperoxide catalyzed by Mn (II) complexes immobilized in the pore channels of mesoporous hexagonal molecular sieves (HMS)," Catalysis Communications, vol. 9, no. 13, pp. 2201-2204, 2008.

[47] T. Sato and T. Komanoya, "Selective oxidation of alcohols with molecular oxygen catalyzed by $\mathrm{Ru} / \mathrm{MnO}_{x} / \mathrm{CeO}_{2}$ under mild conditions," Catalysis Communications, vol. 10, no. 7, pp. 1095-1098, 2009.

[48] Z. Ye, Z. Fu, S. Zhong et al., "Selective oxidation of alcohols with hydrogen peroxide catalyzed by hexadentate binding 8 quinolinolato manganese(III) complexes," Journal of Catalysis, vol. 261, no. 1, pp. 110-115, 2009.

[49] Q. Tang, C. Wu, R. Qiao, Y. Chen, and Y. Yang, "Catalytic performances of $\mathrm{Mn}$-Ni mixed hydroxide catalysts in liquid-phase benzyl alcohol oxidation using molecular oxygen," Applied Catalysis A, vol. 403, no. 1-2, pp. 136-141, 2011.

[50] Y. Guo, J. Zhao, J. Xu et al., "Aerobic oxidation of benzyl alcohol catalyzed by $\mathrm{Cu}-\mathrm{Mn}$ mixed oxides and 2,2,6,6-tetramethylpiperidyl-l-oxyl," Journal of Natural Gas Chemistry, vol. 16, no. 2, pp. 210-212, 2007.

[51] G. Yang, W. Zhu, P. Zhang et al., "Recyclable carbon supported copper-manganese oxide for selective aerobic oxidation of alcohols in combination with 2,2,6,6-tetramethylpiperidyl-1oxyl under neutral condition," Advanced Synthesis \& Catalysis, vol. 350, no. 4, pp. 542-546, 2008.

[52] Q. Tang, X. Gong, P. Zhao, Y. Chen, and Y. Yang, "Copper-manganese oxide catalysts supported on alumina: physicochemical features and catalytic performances in the aerobic oxidation of benzyl alcohol," Applied Catalysis A, vol. 389, no. 1-2, pp. 101-107, 2010.

[53] R. Ali, M. R. Siddiqui, and A. A. Warthan, "Selective oxidation of benzyl alcohol with molecular oxygen over copper-manganese oxide catalyst," Oxidation Communications, vol. 34, p. 778, 2011.

[54] W. Rasband, "ImageJ 1.44O," National Institutes of Health, Bethesda, Md, USA, http://imagej.nih.gov/ij/.

[55] M. R. Morales, B. P. Barbero, and L. E. Cadus, "Evaluation and characterization of $\mathrm{Mn}-\mathrm{Cu}$ mixed oxide catalysts for ethanol total oxidation: influence of copper content," Fuel, vol. 87, no. 7, pp. 1177-1186, 2008

[56] X. Li, J. Xu, L. Zhou et al., "Liquid-phase oxidation of toluene by molecular oxygen over copper manganese oxides," Catalysis Letters, vol. 110, no. 1-2, pp. 149-154, 2006.

[57] G. S. P. Soylu, Z. Ozcelik, and I. Boz, "Total oxidation of toluene over metal oxides supported on a natural clinoptilolitetype zeolite," Chemical Engineering Journal, vol. 162, no. 1, pp. 380-387, 2010.
[58] A. Cecchetto, F. Fontana, F. Minisci, and F. Recupero, "Efficient $\mathrm{Mn}-\mathrm{Cu}$ and $\mathrm{Mn}$-Co-TEMPO-catalysed oxidation of alcohols into aldehydes and ketones by oxygen under mild conditions," Tetrahedron Letters, vol. 42, no. 38, pp. 6651-6653, 2001.

[59] Q. Tang, T. Liu, and Y. Yang, "Role of potassium in the aerobic oxidation of aromatic alcohols over $\mathrm{K}^{+}$-promoted $\mathrm{Mn} / \mathrm{C}$ catalysts," Catalysis Communications, vol. 9, no. 15, pp. 2570-2573, 2008.

[60] G. R. Najafi, "A green and efficient oxidation of benzylic alcohols using $\mathrm{H}_{2} \mathrm{O}_{2}$ catalyzed by Montmorillonite-K10 supported $\mathrm{MnCl}_{2}$," Chinese Chemical Letters, vol. 21, no. 10, pp. 1162-1164, 2010. 

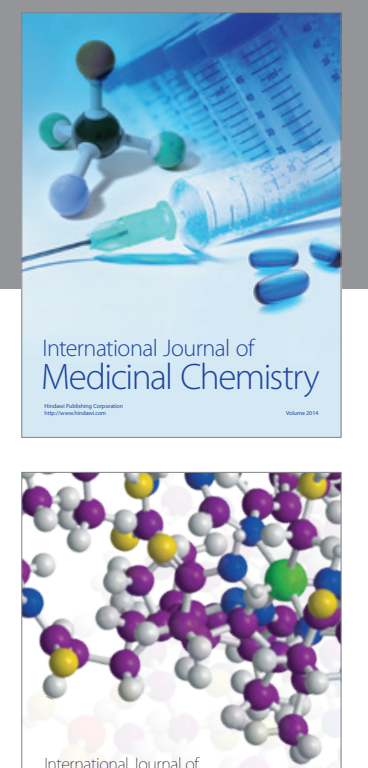

\section{Carbohydrate} Chemistry

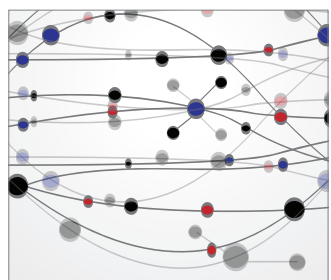

The Scientific World Journal
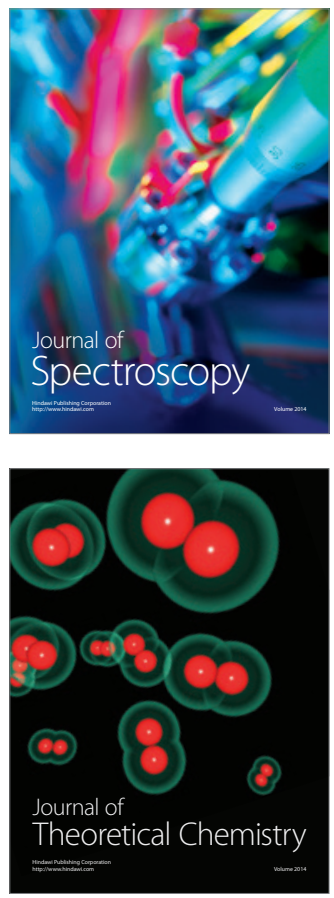
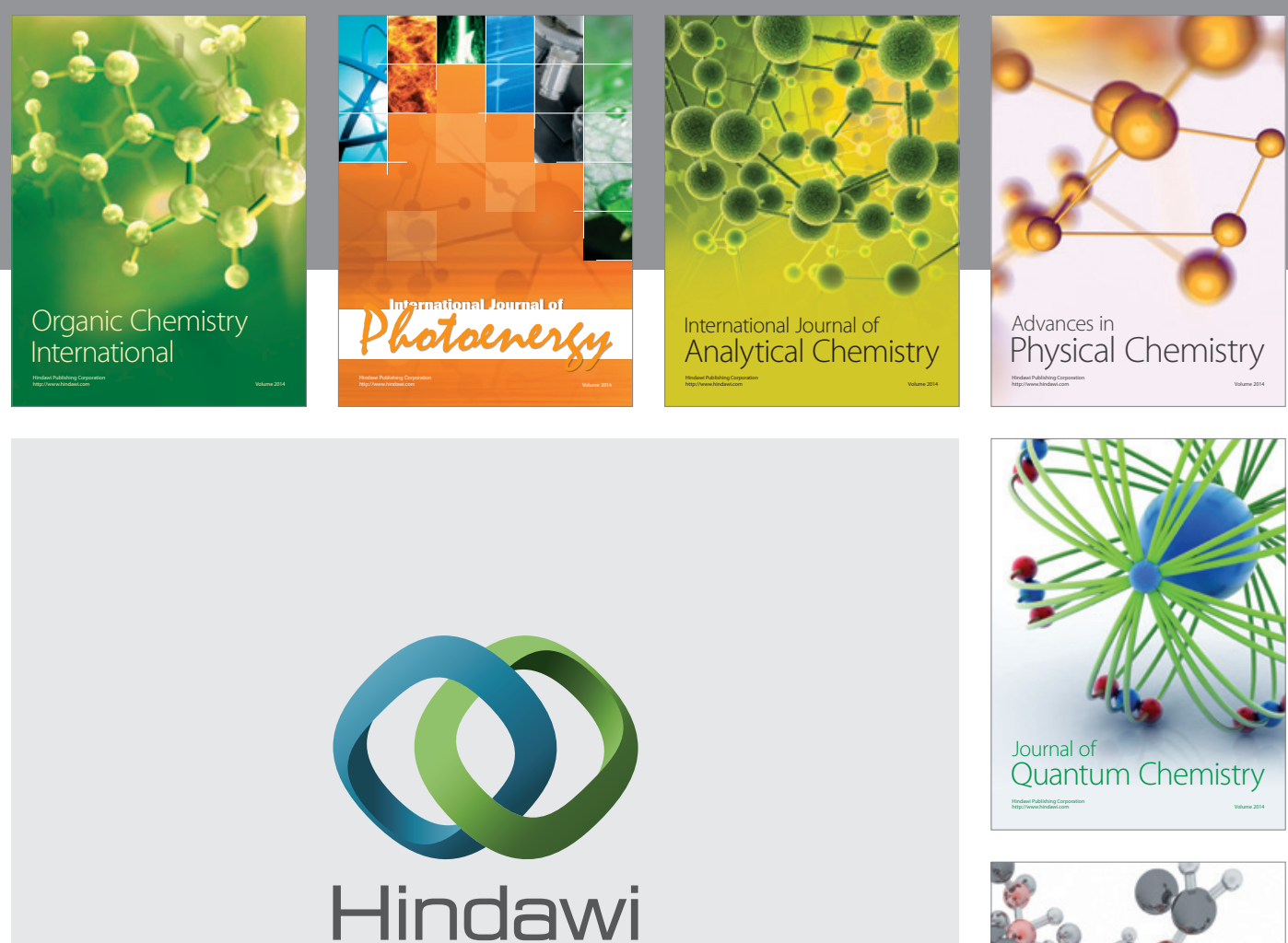

Submit your manuscripts at

http://www.hindawi.com

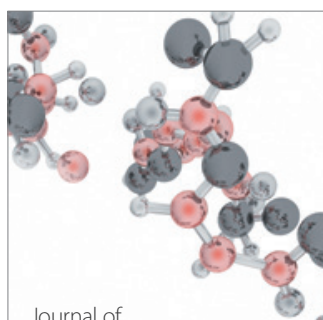

Analytical Methods

in Chemistry

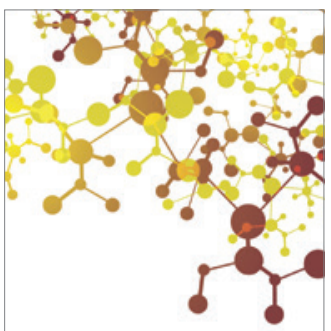

Journal of

Applied Chemistry

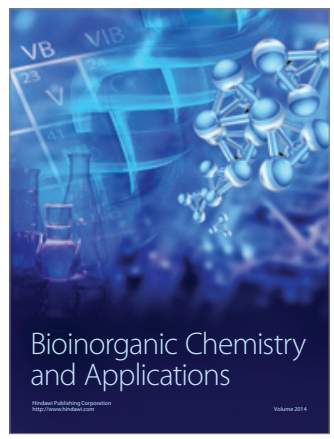

Inorganic Chemistry
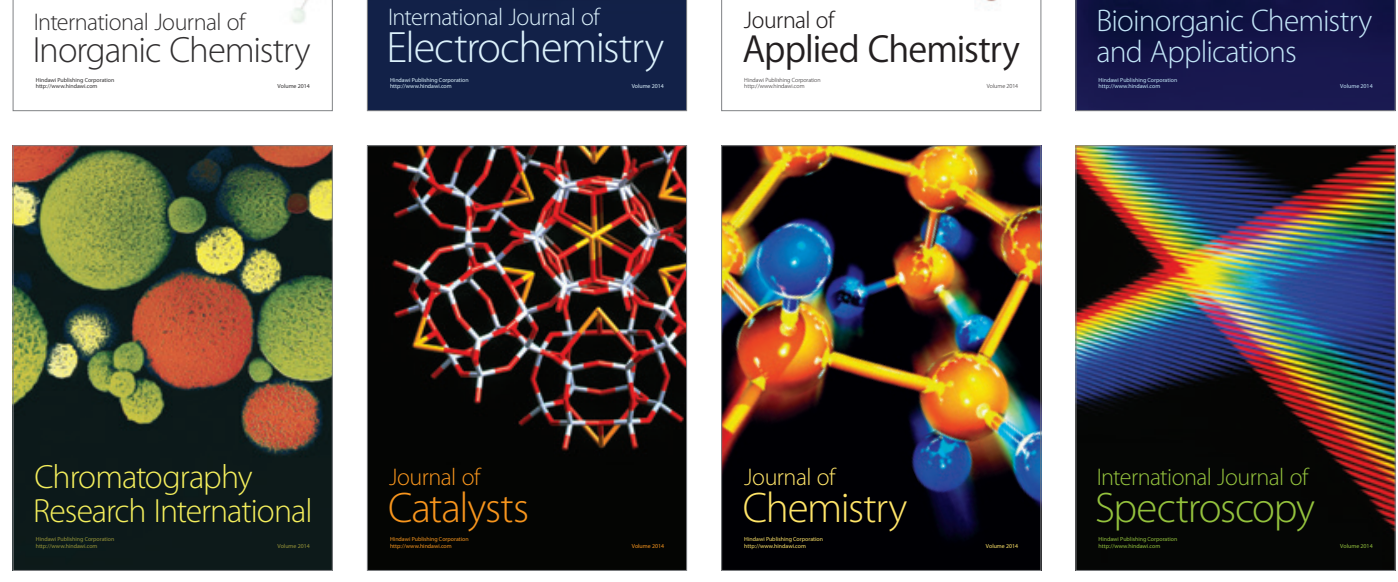